\title{
REIVINDICACIÓN IRREDENTA DE LA MEMORIA HISTÓRICA FEMENINA: LA LUCHA DESDE LA PRISIÓN CONTRA LA DICTADURA ESPAÑOLA
}

\author{
UNREDEEMED VINDICATION OF FEMALE HISTORICAL MEMORY: THE FIGHT \\ FROM PRISON AGAINST THE SPANISH DICTATORSHIP
}

Manuel Pinto Barragán

Universidad Pablo de Olavide

\begin{abstract}
Resumen:
La obra de Dulce Chacón, La voz dormida (2002), apareció en el panorama literario español visibilizando los testimonios de las mujeres presas durante la dictadura franquista. La ficción de la novela propone compensar el déficit de conocimientos históricos sobre ese período y enfatizar el papel de la mujer en la lucha contra el régimen. Este estudio analiza algunos hechos históricos que aparecen en la obra de ficción y como la autora los utiliza como materia diegética para integrarlos en la memoria histórica de la lucha femenina contra los regímenes políticos.
\end{abstract}

\section{Palabras clave:}

memoria histórica, presas políticas, testimonio, dictadura

\section{Abstract:}

Dulce Chacón's novel, La voz dormida (2002), appeared on the Spanish literary scene, thus making the testimonies of women imprisoned during the Franco dictatorship visible. The fiction in the novel aims to compensate the lack of historical knowledge about that period and to highlight the role of women in the fight against the political regime. This paper analyzes some historical facts present in Chacon's work of fiction and how she uses them as linking material to integrate them into the historical memory of the female struggle against political regimes.

\section{Keywords:}

historical memory, female incarceration, testimony, dictatorship 
"La literatura tiene un gran potencial para modificar el imaginario colectivo del pasado y para configurar nuevas memorias"

Elina Liikanen

\section{INTRODUCCIÓN}

El presente trabajo pretende formar parte del compromiso ético que lucha contra el olvido histórico y reivindica la importancia de la participación femenina en las revoluciones sociales. Las conceptualizaciones históricas y políticas examinadas a través de la lente de género ratifican la relevancia de las mujeres en el activismo político y refuerza la visibilidad del colectivo femenino en la historia. Ana Corbalán, en su estudio crítico sobre la resistencia femenina contra las dictaduras, señala que "la participación femenina en varios frentes de resistencia tales como el del exilio, la cárcel y la lucha clandestina, .... pesar de su destacada agencia y militancia política, muchas de estas mujeres han sido totalmente desvinculadas de la historiografía oficial" (Corbalán, 2016: 24). Haciendo referencia al universo penitenciario, cabe definir que el mundo carcelario no es todo aquello que ocurre en el interior de una prisión, sino que abarca la relación entre ese espacio interior con el espacio exterior. Las mujeres presas durante la Guerra Civil española y la dictadura franquista "no fueron simples sujetos de sufrimiento incapaces de algo más que el lamento" (Vinyes, 2010: 14). Algunas de ellas mantuvieron su compromiso social y político con la lucha y las formas alternativas de ser rebeldes con la dictadura incluso dentro de las prisiones. Muchas de esas acciones tuvieron repercusión tanto dentro como fuera de las cárceles. El desafío lo ejercían a través de sus testimonios y memorias - entiéndase éstas como recuerdos o diariosque se propagaban oralmente o por escrito, y a su vez, les servía como mecanismo de resistencia, reivindicando la denuncia, la lucha y el reconocimiento histórico de su militancia antidictatorial (Corbalán, 2016: 71).

Importantes representaciones literarias de la resistencia reivindican el rol femenino durante esos períodos de represión y hacen una firme denuncia hacia la propaganda franquista que ocultaron su lucha. Entre diversas publicaciones sobre la represión franquista hacia las mujeres destaca la obra de Tomasa Cuevas (1917-2007), activista comunista encarcelada en 1939, que es referente de la situación de las presas en las cárceles españolas durante la dictadura. Su obra, Testimonios de mujeres en las cárceles franquistas (2004), es el reclamo de aquellas mujeres y aquellos años que sufrieron la doble condena por motivos políticos e históricos. El análisis de estos hechos está documentado por el historiador Ricard Vinyes. En su estudio, Irredentas: Las presas políticas y sus hijos en las cárceles franquistas (2002 / 2010), relata el sistema carcelario del Nuevo Estado y analiza especialmente el modo en el que las presas políticas construyeron sus vidas hasta mediados de los años cincuenta. En el epílogo, aparece 
un breve relato fechado en 1975, donde se revela hasta qué punto pervivió el proyecto carcelario inicial de la dictadura y "la sorprendente inutilidad del mismo, a pesar de haber dejado a lo largo de cuarenta años un número sin cálculo posible de vidas dañadas" (Vinyes, 2010: 13). Estos textos recogen los testimonios de las mujeres presas que conservaron sus experiencias vitales diferenciadas según la prisión en la que les tocó vivir, pero unidas en la misma resistencia contra la dictadura.

En este mismo sentido se postula la obra de ficción de Dulce Chacón (1954-2003), La voz dormida (2002), donde se reproduce la voz de las mujeres encarceladas, torturadas y desaparecidas durante la Guerra Civil y la posterior dictadura franquista en España. La novela rebasa los límites de la verosimilitud con los efectos entre realidad y ficción, debido a la narración constantemente mezclada entre los testimonios reales de las víctimas y las voces de los personajes ficticios. Existe una reticencia en alejarse de una situación imaginaria y predomina el reportaje periodístico o documental de los hechos históricos. Este texto, que abusa de la investigación histórica, se convierte en una novela donde predomina la docuficción, en el sentido expuesto por Christian Von Tschilschke y citado por Hans Lauge Hansen y Juan Carlos Cruz en su ensayo "Literatura y memoria cultural en España (2000-2010)":

un discurso narrativo híbrido, caracterizado [...] por la inclusión en el discurso novelístico de fragmentos de otros discursos sociales, como, por ejemplo, recortes de periódicos, párrafos de libros historiográficos sobre el período en cuestión, informes de dudosa oficialidad, extractos de manuales de tortura, testimonios orales en primera persona; pero también aparte metaficticios que el narrador destina al lector y en los que se describe el mismo oficio de narrar (Hansen y Cruz, 2012: 25).

La obra sigue una estética posmodernista donde se compagina información y datos verídicos con elementos ficticios. La unión de estos elementos forma un marco narrativo sobre el que se proyecta la trama en el contexto histórico determinado. Como indica Hans Lauge Hansen y Juan Carlos Cruz, “de esa unión de elementos surge la novela adscrita al modelo narratológico documentalista que exhibe una parte importante de las obras que han activado el tema de la memoria cultural durante la última década en España (Hansen y Cruz, 2012: 24). En este caso, las protagonistas de la novela cumplen un fin didáctico, mostrando así la resistencia y la lucha constante de las mujeres que sufrieron la represión directa de la dictadura.

\section{EL TESTIMONIO HISTÓRICO EN EL TEXTO NARRATIVO}

La obra literaria de Dulce Chacón presenta una perspectiva histórica subjetiva de la Guerra Civil y la postguerra mediante testimonios crítico-sociales de las protagonistas. Estos testimonios, denominados "realismo narrativo", enmarca literariamente la novela 
en una obra memorística. Carmen Servén, en su estudio "La narrativa de Dulce Chacón: memoria de las perdedoras" corrobora esta idea afirmando que "la memoria literaria de los conflictos que viven las mujeres en nuestra sociedad es parte constitutiva del legado de Dulce Chacón" (2006: 585). Este estudio no pasa por alto la belleza narrativa de esta obra y el buen uso de la prosa, con el propósito de deleitar al lector con historias aparentemente tristes, como son la mayoría de los acontecimientos que muestra el sufrimiento de las mujeres en la cárcel, el trato inhumano y las injusticias que padecen por parte de las autoridades carcelarias y judiciales. No se debe cuestionar el sentido histórico de la obra en general, que ya sabemos de su carácter ficticio, pero el marco histórico y las protagonistas ofrecen una caracterización de los personajes femeninos en los que se reivindican sus actos memorísticos. La finalidad de recordar todo lo que estas mujeres habían perdido antes, durante y después de la contienda bélica es su legado transgresor para generaciones futuras. Las acciones orales y escritas que las presas producen durante su reclusión servirán de actos transgresores contra el olvido histórico al que estaban condenadas. Su lucha no se vería reconocida en el futuro sino hubiera sido por esas acciones.

Valga como ejemplo de transgresión el mensaje que se reproduce de la última carta de Julia Conesa, activista política fusilada que formó parte del grupo de Las Trece Rosas y que aparece en la novela como ese personaje histórico que lucha contra su injusto final: “Que mi nombre no se borre en la historia" (Chacón, 2002: 222). Este personaje que podría haber quedado olvidado, dejó su legado histórico con su escrito y vence así a la exclusión de la Historia. De igual manera, "el cuaderno azul" donde Hortensia escribe su historia y dejará como legado a su hija Tensi, servirá como mensaje y texto transgresor del olvido, es decir, su compromiso por la lucha activa en contra del régimen será transmitido a la siguiente generación: "Se pasaba gran parte del día escribiendo en un cuaderno azul" (Chacón, 2002: 13).

En la novela no se distingue las peripecias ficticias de las verídicas, ya que constantemente se mezclan los acontecimientos de personajes históricos con los recuerdos de los personajes ficticios, junto a los conocimientos históricos del propio lector. De este modo comparte similares características con la novela histórica, diferenciándose de éstas en la reflexión sociocultural y la rememoración histórica que plantea la obra, es decir, el acto de conmemorar la lucha de las mujeres presas y darle voz a los acontecimientos que han quedado ocultos. Atendiendo al concepto de "Historical remembrance" propuesto por Jay Winter se integra en ese "campo discursivo" constituido por los discursos historiográficos, biográficos y ficticios que aparecen conjuntados en la novela (Winter, 2006, 3). Los sucesos de ficción proceden de los recuerdos y testimonios de personajes históricos reconocibles que plasman una realidad aparente en la obra literaria. Así pues, se puede afirmar que el concepto 
de realidad que maneja la autora en esta obra es un concepto más amplio, donde se incluyen recuerdos y testimonios reales de personajes que hablan de hechos históricos. No existen límites entre los elementos de lo real y lo literario. A partir de década de los 90, y hasta la actualidad, el tema del conflicto bélico y los textos testimoniales tuvieron un gran auge, integrando material histórico en la novela. Tal es el caso en la obra de Chacón donde "el material histórico fue trabajado con mayor rigor" (Milquet, 2012: 111).

El hecho de que imaginación e Historia se presenten en La voz dormida como agentes que muestran tanto la versión real de los acontecimientos como peripecias ficticias, permite conocer los resultados de las investigaciones históricas de ese período. Desde una perspectiva literaria vamos conociendo las relaciones sociales de las personas que fueron víctimas de estos sucesos y su lucha inagotable contra la injusticia de la dictadura. Como no podía ser de otra forma, la historia oficial que ha quedado está filtrada por la propaganda franquista, la censura y las distintas interpretaciones que desde la actualidad se realizan a los acontecimientos pretéritos.

El personaje literario que aparece en la novela de Chacón con el nombre de Tomasa, no es más que un guiño literario a la persona de Tomasa Cuevas, una activista de Guadalajara, detenida y encarcelada en 1939. Fue condenada a treinta años de prisión, de los que solo cumplió cinco en distintas cárceles españolas. Tomasa Cuevas es un referente en la lucha antifranquista desde la perspectiva femenina y durante la democracia publicó los testimonios y las memorias de muchas de las mujeres que habían sido condenadas y encarceladas durante la dictadura. El historiador Ricard Vinyes describe en su estudio la publicación de Tomasa como una gran obra de referencia histórica y señala que "sus tres volúmenes, de una riqueza excepcional, son una poderosa fuente primaria y algo más: una de las mejores contribuciones cívicas de aquellas mujeres irredentas que quisieron ser historiadoras de sí mismas" (Vinyes, 2010: 16).

\section{LA LUCHA Y LA REIVINDICACIÓN FEMENINA DESDE LA PRISIÓN}

Las protagonistas en la novela representan las diversas posturas de las mujeres con respecto a la lucha política y social que les había tocado vivir. Muchas de ellas son madres, hermanas, esposas, hijas y huérfanas que se proponen superar con creces las vicisitudes de una sociedad machista en guerra civil. Estos personajes femeninos hacen reflexionar sobre la lucha de la víctima en distintos frentes; la derrota de la guerra, la represión posterior ejercida por los vencidos y la violencia añadida al género femenino. Sophie Milquet apunta acertadamente estos aspectos en su estudio sobre "Escribir el trauma femenino", en el que plantea "tres elementos, separados por las 
necesidades de la explicación, pero en realidad estrechamente vinculados entre sí: el cuerpo femenino, la maternidad y el papel social femenino" (2012: 114).

Las narrativas de memorias de personas encarceladas por motivos políticos no solo enfatizan el protagonismo individual, sino que son textos representando a un colectivo más numeroso, es decir, son testimonios que han sido escritos para llevar a cabo una lucha común. En muchos casos es una denuncia colectiva desde una visión individual, en otros, el despertar de la conciencia a una sociedad que ha vivido ajena a estos acontecimientos. Las protagonistas ficticias de la obra literaria funcionan como portavoces de todas las mujeres y reclusas durante la Guerra Civil y la posterior dictadura. Esa lucha desde la prisión se refleja desde una variedad de enfoques con el testimonio de las adversidades, las enfermedades, las injusticias, las torturas, las violaciones, los procedimientos judiciales irregulares, la separación forzada de los hijos menores, la desaparición y pérdida de familiares. En definitiva, existe un trato infrahumano recibido por estas mujeres y que queda representado en esta obra literaria como ficción, pero prosigue con la lucha que se efectúa desde el espacio interno de las prisiones al espacio exterior, con la publicación, conmemoración y reivindicación de la historia de sus vidas.

La voz dormida de Dulce Chacón nace precisamente de esa necesidad de contar la Historia. El análisis de la transmisión de testimonios obedece tanto a la necesidad de romper el silencio de las víctimas, como de reconstruir un pasado, algo que dejar a los supervivientes y a las generaciones futuras. En la novela, esta idea aparece expuesta en la voz de Hortensia, que pone énfasis en el asunto histórico de la perpetuidad y anima a sus compañeras para continuar con la lucha:

- Hay que sobrevivir, camaradas. Sólo tenemos esa obligación. Sobrevivir.

-Sobrevivir, sobrevivir, ¿para qué carajo queremos sobrevivir?

- Para contar la historia, Tomasa.

- ¿Y la dignidad? ¿Alguien va a contar cómo perdimos la dignidad?

- No hemos perdido la dignidad.

-No, sólo hemos perdido la guerra, ¿verdad? Eso es lo que creéis todas, que hemos perdido la guerra.

- No habremos perdido hasta que estemos muertas, pero no se lo vamos a poner tan fácil. Locuras, las precisas, ni una más. Resistir es vencer. (Chacón, 2002: 13738)

Con el propósito de la transmisión histórica, las protagonistas prosiguen su lucha y será así como las generaciones futuras conocerán el esfuerzo y la reivindicación de estas mujeres presas, que fueron juzgadas y condenadas peleando por la libertad. La diferencia entre los acontecimientos que narra la novela con aquellos que expone la historia oficial es notoria. La Historia no acepta elementos de ficción como sí lo hace la literatura, aunque ambos registros transforman los acontecimientos en actos de 
transmisión lingüística. Los textos históricos incluyen datos sobre el pasado al igual que conceptos teóricos que ayudan a explicar estos datos. Uno de los autores que más ha contribuido a revivir el debate entre Historia y lenguaje es el historiador y crítico literario Hayden White. En su obra, Metahistoria: La imaginación histórica en la Europa del siglo XIX (1992), analiza los relatos históricos en términos de géneros literarios. Este "nuevo historicismo" surgió en los Estados Unidos como un nuevo modo de conocimiento de la historia y como una forma de relacionar la Historia con la literatura. El lenguaje opera como una estructura prefigurante del objeto de conocimiento que implica que los conceptos, las explicaciones y los significados que los historiadores atribuyen a los hechos históricos, no emanan de los hechos mismos, sino que les son impuestos desde afuera. Así pues, si el lenguaje no es sólo un medio de comunicación, entonces los hechos no son meras proyecciones de los acontecimientos, sino efectos de la misma mediación lingüística (White, 1992: 13).

El afán reparador y la vocación didáctica de esta novela queda plasmado en los testimonios que se vierten a través de sus protagonistas y no cabe duda de que pasa a formar parte de la producción cultural vinculada con la recuperación de la memoria histórica española, por los datos e información historiográfica que en ella aparecen. La autora, que no vivió personalmente los sucesos narrados a los que hace referencia en su obra, se ha hecho eco de la falta historiográfica de esos acontecimientos. Ante esa falta de historias sobre las mujeres que perdieron la guerra, ha intentado reproducir el pasado, de manera que la novela pase a ser un acto abierto de memoria. A su vez, se hace portadora y restauradora de aquellas voces e historias que se diluyeron con el paso del tiempo y quedaron silenciadas por la represión franquista. Hoy forma parte de una reconstrucción imposible, al menos en términos historiográficos, ya que los historiadores no tienen acceso a todos los archivos, y en su caso, estos están dañados, cuando no destruidos. Es, por tanto, tarea de la ficción rescatar esos sucesos históricos que han quedado olvidados en el pasado. La novela imagina lo que pudiera haber ocurrido, construyendo un discurso historiográfico alternativo, a la espera de poder tener acceso a los documentos estancados en los archivos.

\section{El TRAUMA DE LA SUPERVIVENCIA}

Las protagonistas encarceladas comparten, además de la privación de libertad, el trauma de haber perdido a algún familiar. Esta perdida se produce por la muerte del familiar o la desaparición de la persona, ya que desconoce su paradero. Tomasa pierde a sus hijos y a su esposo, que fueron fusilados. Ella redime su pena manteniéndose en la lucha. Es el personaje más combativo y rebelde de la prisión, pero que logra sobrevivir con la idea de mirar al futuro y sobrevivir. Reme, al estar presa, no puede hacerse cargo de su familia, en especial de su hijo menor, que está discapacitado, y 
le hace sentir que ha abandonado a sus seres queridos. Es el personaje con mayores esperanzas de salir y regresar a su hogar para cuidar de los suyos. Por otra parte, el personaje de Elvira es la hija huérfana y la más débil del grupo de mujeres. Con ella se conoce el vínculo militar de su padre, que muere en combate, y la lucha activa de su hermano Paulino. Después de la muerte de su madre, es su abuelo quien visita a Elvira en la prisión, pero con bastantes dificultades para comunicarse.

Entre todas las protagonistas, sobresalen la figura de Hortensia, su hija Tensi y su hermana Pepita. Las tres son miembros de una familia que hace vínculo de unión y cohesión de la trama en las tres partes en la que se divide la novela. La primera parte enfocada en la presentación de los personajes, sus vidas y los motivos de lucha por los que fueron detenidas. La segunda parte se centra en el juicio, condena y fusilamiento de Hortensia, después de tener a su hija Tensi. En la tercera parte se conoce el desenlace amoroso entre Pepita y Paulino junto con el desarrollo de la infancia a la madurez de Tensi, que va conociendo la historia sobre la muerte de sus padres. El lector va conociendo los detalles de la trama mediante escenas retrospectivas y estrategias narrativas como la prolepsis, que consiste en anticipar al lector lo que va a suceder. Este uso anticipatorio de los hechos los realiza el narrador omnisciente que conoce todo de los personajes y narra la historia desde los límites de la novela.

En este estudio destacamos a estas tres protagonistas ya que con ellas se expone una situación particular de las mujeres presas durante la dictadura, como son los casos de robos de bebés y la expropiación de menores durante el régimen franquista. Si bien es cierto que la hermana de Hortensia, Pepita, logra rescatar al bebé de la prisión cuando fusilan a la madre, no obstante, es evidente que la recién nacida estuvo en "la zona de riesgo", tal y como documenta el historiador Ricard Vinyes en su estudio sobre la situación de las madres y sus bebés en las cárceles durante la postguerra (Vinyes, 2010: 78). El estudio del historiador muestra el procedimiento llevado a cabo por el Estado para legislar sobre la situación infantil en los presidios entre 1940 y 1944, junto con las operaciones de traslados infantiles anotadas por los funcionarios como "Destacamento hospicio" (Vinyes, 2010: 79). Queda evidencia, con la sentencia que aparece al final de la segunda parte de la novela, que las fechas en las que se realizó la ejecución de Hortensia tuvo que estar comprendida entre esos años que señala el historiador en su estudio (Chacón, 2002: 247-248). Esto dejó a numerosas madres y familias de represaliadas sin la custodia de sus hijos, y a estos, huérfanos de sus padres.

La hija de Hortensia no es el único personaje que es huérfano en la novela. Ya comentamos el caso de Elvira, la compañera de Hortensia, que perdió a su padre en combate y a su madre enferma. En el caso de Reme, se ve forzada a estar recluida en la cárcel alejada de su familia y sin poder atender a su hijo discapacitado, hasta que consigue la libertad condicional y logra reunirse con su familia. También Hortensia 
y Pepita perdieron a su madre antes de comenzar la guerra y a su padre cuando se trasladaron a Madrid, pero es la hija de Hortensia el personaje que enfatiza su estado de orfandad. Ella queda huérfana al morir su padre Felipe en una emboscada y a su madre, que fue condenada a muerte. La ausencia de sus padres se destaca durante la tercera parte de la novela, junto con el esfuerzo de su tía Pepita por recuperar al bebé recién nacido de "la zona de riesgo":

Pepita irá a la prisión de Ventas a preguntar por Hortensia, tal y como le indicó Mercedes el día que nació la niña. [...] Yo soy su tía y soy yo quien me la tengo que llevar cuando saquen a mi hermana. No sea que vaya a ser que crean que no tiene a nadie, pero me tiene a mí. Es por eso, y por nada más que por eso, que preciso saber cuándo... (Chacón, 2002: 235)

Esta cita de la novela coincide con el testimonio que realizó Balbina Torres a los periodistas Montse Armengou y Ricard Belis, y quedó registrado y publicado en el libro Los niños perdidos del franquismo (2002), como parte de una investigación que realizaron para el documental del mismo nombre emitido en el programa 30 minuts de la Televisió de Catalunya (TV3):

\footnotetext{
Balbina Torres recuerda el caso de Concha Madera: «Concha Madera, que era de Asturias, llegó a Ventas casi inválida de las palizas que le habían dado. Vino con su hijo chiquitito. Le sacaron el niño y ella nunca llegó saber dónde lo llevaron. Allí quien mandaba sobre nosotras y nuestros hijos eran ellos y no te daban explicaciones». Una vez que les habían quitado el niño, era imposible reclamarlo. No tenían ningún derecho. No eran nadie. Y como el niño no había sido registrado en la cárcel podían hacer con él lo que quisieran. Tenían potestad absoluta sobre los niños y sus madres (Vinyes, 2002: 104).
}

El asunto sobrelos niños expropiados durante el régimen franquista fue documentado por historiadores y agentes judiciales a raíz de los testimonios de mujeres que fueron víctimas de esos robos en hospitales, clínicas y prisiones de distintos puntos de España. El trabajo conjunto de las diferentes asociaciones sobre la recuperación de la memoria histórica en España ha colaborado a la investigación sobre este tema, de manera que se involucra en la búsqueda de la verdadera identidad de los bebés robados como parte del proceso histórico al que se enfrentan. Las distintas leyes que han propuesto las autoridades sobre la protección del menor y la desaparición forzada de personas son presentadas por el jurista e investigador de derecho Miguel Ángel Rodríguez Arias en su libro El caso de los niños perdidos del franquismo: Crimen contra la humanidad (2008). El jurista concluye calificando estos hechos como crímenes contra la humanidad por su carácter generalizado y sistemático contra un determinado colectivo. Asimismo, esta investigación llama la atención a los organismos internacionales y nacionales para esclarecer y resolver el conflicto español de forma que sugiere una inmediata revisión del sistema jurídico en España referente al caso de los niños expropiados durante el franquismo (Rodríguez, 2008: 33). 
Diferentes organismos internacionales han intervenido recientemente sobre los casos de desapariciones forzadas de personas y la condena pública de esos delitos que afectan a la legislación española en lo referente a las infracciones cometidas durante la Guerra Civil y posterior dictadura. La Asamblea Parlamentaria del Consejo de Europa del 17 de marzo de 2006 condenó la dictadura franquista y reconoció por primera vez a los "niños perdidos" como víctimas del franquismo, ya que "se trata de hijos de presas cuyos apellidos fueron modificados para permitir su adopción por familias adeptas al régimen" (Rodríguez, 2008: 329). Igualmente, la investigación corrobora que los delitos cometidos durante esa época son casos que aún no han prescrito, debido a que muchos individuos en la actualidad siguen llevando una identidad falsa (Rodríguez, 2008: 20).

El origen por el cual los hijos de las mujeres encarceladas por motivos políticos fueran separados de sus madres biológicas se produce mediante las investigaciones que llevó a cabo el psiquiatra Antonio Vallejo Nájera (1889-1960) durante los años de la Guerra Civil y la postguerra. En su estudio pretendía demostrar el grado de inferioridad mental que presentaban los comunistas y republicanos capturados durante el conflicto bélico. Los resultados de esas investigaciones fueron determinantes para el futuro de miles de niños que caían prisioneros junto a sus madres. Las reclusas de la cárcel de Málaga con la que Vallejo Nájera realizó sus investigaciones en 1939 formaban un grupo de cincuenta presas políticas. Las conclusiones de estas investigaciones fueron nefastas para las madres encarceladas y para el colectivo femenino en general. El psiquiatra llegó a considerar a estas presas con una capacidad intelectual que superaba la media y resultaba patente el rencor y el resentimiento político contra el régimen franquista. El efecto de este informe resultó en el alejamiento de la mujer a cualquier acceso o participación activa de la política, así como a la resolución de las características psicológicas innatas y degenerativas históricas que la hacían un ser inferior. (Vinyes, 2010: 51). A raíz de esta investigación, la segregación sistemática entre las madres y los hijos se puso en práctica desde 1940 con la Orden legislativa del 30 de marzo de ese mismo año. Esta Orden dictaminaba las normas sobre la permanencia de los hijos de las reclusas hasta los tres años de edad con el derecho de poder amamantar a sus hijos. Muchas presas fueron testigos de estos procedimientos y las condiciones inhumanas en las que se encontraban las madres y sus hijos (Vinyes, 2010: 53)

\section{Conclusión. El legado escrito}

A través de los datos históricos, considerados acontecimientos históricos reales, y el panorama político-legislativo sobre el caso de los niños expropiados de sus madres durante el franquismo, Dulce Chacón muestra un mundo paralelo, un simulacro de ficción en el que aparecen muchos de los hechos y personajes que vivieron estos acontecimientos. Las estrategias peculiares de verosimilitud utilizadas en la novela 
conllevan a la resonancia de lugares, personajes y hechos. La cárcel de Ventas de Madrid, donde transcurre la historia en la novela, es una de las prisiones de mujeres más señaladas por los historiadores. Durante los primeros años de la postguerra la prisión albergó a 11.000 presas donde había capacidad para 500 (Vinyes, 2010: 72). Las protagonistas de La voz dormida hacen referencia a las historias de las mujeres encarceladas y sus testimonios. En el epílogo de la novela, la propia autora agradece y menciona a todas ellas: "Mi gratitud a todas las personas que me han regalado su historia" (Chacón, 2002, 425). En la obra se exponen varios acontecimientos relacionados con el encarcelamiento, la lucha militante de las mujeres y la vida en la cárcel y fuera de ella. Destacan las historias de Los Maquis con los personajes masculinos, las luchas internas de prisión protagonizadas por Tomasa, el proceso judicial por el cual ejecutan a Hortensia, las penurias de las presas y sus familiares que van conformando la novela. En este estudio, cobra una importante atención el artilugio y la vida que Hortensia ha ido confeccionando durante los últimos días en prisión y de su vida: el cuaderno azul y su hija Tensi.

El personaje de Hortensia está presente en dos tercios de la obra y desde el inicio, se informa al lector sobre su final: "La mujer que iba a morir se llamaba Hortensia" (Chacón, 2002, 13). Lo que el lector va descubriendo es el proceso de lucha y continuidad que la protagonista está realizando para generaciones futuras, engendrar a su hija y abastecerla con la información de su origen. Es ese legado transgresor lo que la protagonista proporciona a su hija, y la autora nos entrega a los lectores de la novela. El acto de la escritura, que Hortensia aprendió por medio de Paulino, dejando plasmada su historia en el papel del cuaderno, suministrado por Felipe y Pepita, es el legado de su lucha y resistencia para defender la libertad. El acto de transmisión lo inicia Hortensia desde el interior de la cárcel, lo continúa Pepita al responsabilizarse del cuidado de Tensi, pero lo completa la hija al cumplir los dieciocho años y decide unirse al Partido Comunista. De esta forma, se completa el proceso de transmisión de los recuerdos de la primera a la siguiente generación.

Este proceso de lucha y transmisión se inicia con el personaje de Hortensia en la novela. Una militante activa que es capturada y encarcelada, pero continúa su lucha desde la prisión mediante el acto de la escritura en su cuaderno azul. Conocedora de su fatal destino, pretende dejar el legado de su historia a su hija. Su hermana Pepita juega un papel trascendental en la consecución de este cometido, rescatando a la niña de la cárcel y guardando con recelo los escritos y demás objetos de Hortensia para ser transmitidos a la próxima generación. La hija Tensi, heredera de este legado transgresor, recupera todo este material documental y continúa con la lucha iniciada por su madre y conservada por su tía en la clandestinidad. Esta memoria recuperada se inserta en la intertextualidad que constituye los actos de postmemoria, término 
éste que "resulta útil por su diferenciación con 'memoria' y su énfasis en el proceso de transmisión" (Portela, 2007:6). Atendiendo a la idea de Marianne Hirsch sobre la función de la memoria y que Edurne Portela tan acertadamente utiliza para analizar la novela de Dulce Chacón, se entiende que:

El argumento de base que defiende Hirsch y que creo que puede ser de utilidad para comprender el trabajo de Dulce Chacón y su valor en el actual debate sobre la memoria de la Guerra Civil y el franquismo en España, es que la segunda generación adopta el trauma de la primera no para reiterarlo de manera melancólica, sino para conseguir avanzar positivamente en el trabajo de duelo (Portela, 2007: 6).

Esta es la postura que toma la consecución de la lucha contra la dictadura desde la prisión hacia el exterior, promover con el acto de escritura un activismo futuro. Según Portela,

Chacón opta en su narrativa por crear una transmisión indirecta entre la madre y la hija primero a través de la palabra escrita, una palabra que en el caso de Hortensia no ha sido silenciada o amedrentada por la represión, ya que sus cuadernos narran la historia de su lucha política protegida por la paradójica libertad que le otorgan el aislamiento de su celda y la inmediatez de su muerte (Portela, 2007: 10).

Esa transmisión de la historia que realiza la protagonista con su hija se ve reflejada en el acto de escritura de la autora con sus lectores, transmitir las memorias de los vencidos frente a la memoria de los vencedores, para continuar el activismo femenino contra la opresión y las dictaduras.

La novela se inserta en el corpus relacionado con la recuperación de la memoria histórica y transmite la responsabilidad del trabajo de la postmemoria con las generaciones anteriores y futuras. La literatura aquí propone una continuación de lucha contra acontecimientos históricos que no fueron reseñados durante la dictadura y recrea el proceso traumático para superarlo. Tras este análisis, nos percatamos que esta novela de ficción inserta una base firme de realidad y testimonios que se presenta para defender a las vencidas en la guerra y posterior dictadura. Igualmente, se completa la historia de personas olvidadas que gracias a Chacón han sido recuperadas. La reivindicación de las presas durante la dictadura franquista se trasmite en la actualidad mediante esta novela de ficción, pero en la cual encontramos además de la lucha, el sufrimiento y las condiciones de estas mujeres en las cárceles de la postguerra.

\section{REFERENCIAS BIBLIOGRÁFICAS}

Chacón, Dulce. La voz dormida. Barcelona, Penguin Random House, 2019.

Corbalán, Ana. Memorias fragmentadas. Una mirada trasatlántica a la resistencia femenina contra las dictaduras, Madrid, Iberoamericana, 2016. 
Cuevas Gutiérrez, Tomasa; Montes Salguero, Jorge, ed. Testimonios de mujeres en las cárceles franquistas. Huesca, Instituto de Estudios Altoaragoneses, 2004.

Hansen, Hans Lauge y Juan Carlos Cruz. “Literatura y memoria cultural en España (2000-2010)". La memoria novelada: Hibridación de géneros y metaficción en la novela española sobre la guerra civil y el franquismo (2000-2010). Hans Lauge Hansen y Juan Carlos Cruz Suárez, eds. Berg, Peter Lang, 2012, pp. 21-41.

Liikanen, Elina. El papel de la literatura en la construcción de la memoria cultural: tres modos de representar la Guerra Civil y el franquismo en la novela española actual. Universidad de Helsinki. 13 Julio 2015, pp. 1-17. Internet 20-09-19.

Milquet, Sophie. “Escribir el trauma en femenino: las obras de Agustín Gómez-Arcos y Dulce Chacón”, Bulletin of Spanish Studies, 89 (2012), pp. 109-121.

Portela, Edurne M., “Hijos del silencio: Intertextualidad, paratextualidad y postmemoria en La voz dormida de Dulce Chacón", Revista de Estudios Hispánicos, 41 (2007), pp. $1-21$.

Rodríguez Arias, Miguel Ángel. El caso de los niños perdidos del franquismo: Crimen contra la humanidad. Valencia, Tirant lo Blanch, 2008.

Servén, Carmen. “La narrativa de Dulce Chacón: memoria de las perdedoras”, ARBOR Ciencia, Pensamiento y Cultura, 721 (2006), pp. 583-591.

Tschilschke, Christian Von. “Docuficción biográfica: Las esquinas del aire (2000), de Juan Manuel de Prada y Soldados de Salamina (2001), de Javier Cercas". Docuficción: Enlaces entre Ficción y No-Ficción en la cultura española actual. Christian Von Tschilschke y Dagmar Schmelzer, eds. Madrid, Iberoamericana, 2010, pp. 181-199.

Vinyes, Ricard. Irredentas: Las presas políticas y sus hijos en las cárceles franquistas. Madrid, Planeta, 2010.

Vinyes, Ricard, Armengou, Montse y Belis, Ricard. Los niños perdidos del franquismo. Barcelona, Plaza y Janés, 2002.

White, Hayden V. Metahistoria: La imaginación histórica en la Europa del siglo XIX. México, Fondo de Cultura Económica, 1992.

Winter, Jay. Remembering War. The Great War Between Memory and History in Twentieth Century. New Haven \& London: Yale University Press. 2006. 